\title{
Thermochemical Characterization of Rice Husk Coryza Sativa LinnJ for Power Generation
}

\author{
Nikdalila Radenahmad \\ Md Sumon Reza \\ Muhammad S. Abu Bakar \\ Abul K. Azad* \\ Faculty of Integrated Technologies, Universiti Brunei Darussalam, Jalan Tungku Link, Gadong \\ BE 1410, Brunei Darussalam \\ ‘e-mail: abul.azad@ubd.edu.bn
}

Rice husk is biomass that can be utilized as fuel for biomass gasification as a renewable energy source. In this paper, thermochemical methods were used to determine the higher heating values, moisture content, bulk density, pellet density, microstructure, and elemental composition of Thai Rice Husk (Oryza Sativa Linn). The heating energy was analyzed using a bomb calorimeter, which showed a higher heating value of $15.46 \mathrm{MJ} / \mathrm{kg}$. Determination of pellet density through rice husk powder pelletization exhibited a value of $1.028 \mathrm{~g} / \mathrm{cm} 3$, while moisture content was $5.017 \mathrm{wt} \%$. The heating value and moisture content revealed good agreement with the literature values, indicating the potentiality of rice hush for energy generation. Scanning electron microscopy (SEM) showed that the raw rice husk and its ash have similar porosity types but different bulk structure. Elemental analysis using energy dispersive $X$-ray (EDX) indicated that rice husk contains $\mathrm{O}, \mathrm{Si}, \mathrm{C}$ while $\mathrm{O}$ and $\mathrm{C}$ percentages were drastically decreased during combustion. The obtained heating value and moisture content proved that rice husk could be used as a bio-energy source in biomass gasification for power generation.

Keywords: Bomb calorimeter; Elemental analysis; Higher Heating Value; Rice husk; SEM-EDX

\section{INTRODUCTION}

In the present time, biomass has become a potential energy resource in the science and engineering research sector (Hayati et al. 2019). It is a strong candidate that can be transformed into direct energy by its abundance (Reza et al. 2019). Rice husk is a residue from rice farming, which is about $20 \%$ of paddy by weight and has been a promising renewable and sustainable energy resource (Yoon et al.
2012). Rice husk can be utilized as a resource for power generation, especially for small-scale output using direct combustion or gasification technologies (Rizkiana et al. 2018). In addition, activated carbon can be produced from rice husk for water purification (Ahiduzzaman et al. 2016).

Rice husk is available in rice-producing countries, e.g., India, China, Indonesia, Bangladesh, Thailand, Vietnam, Burma, Philippines, Cambodia, and Pakistan (the 
top 10 countries of rice produced in the world) (Radenahmad et al. 2018). The rice production capacity around the world has shown in Figure 1. In this research, rice husk species Oryza Sativa L. from Yala, a province in southern Thailand, has been used to investigate its potentiality for energy production. Oryza sativa rice is not only originated in Thailand but also in India and south China as well. This rice species is currently planted in wet tropical, semitropical, and warm temperate areas worldwide (Pranolo et al. 2010).

Table 1 shows the biomass database of rice husk and some other biomass (e.g., palm kernel shell and rubberwood sawdust) from southern Thailand, produced and used completely $100 \%$ in energy production. In Thailand, rice husk is obtained as $21 \%$ of rice products. From this comparison, it is clear that rice husks have a high potentiality to be an alternative source of renewable energy.

Table 1. The potential of biomass in 2013, southern Thailand.

\begin{tabular}{|c|c|c|c|c|}
\hline Biomass & $\begin{array}{c}\text { Biomass } \\
\text { quantity (ton) }\end{array}$ & $\begin{array}{c}\text { Biomass used } \\
\text { (ton) }\end{array}$ & $\begin{array}{c}\text { Biomass } \\
\text { remained (ton) }\end{array}$ & $\begin{array}{l}\text { Biomass } \\
\text { usage (\%) }\end{array}$ \\
\hline \multicolumn{5}{|l|}{ In-season rice } \\
\hline - Rice straw & $216,394.21$ & $216,394.21$ & - & 100.00 \\
\hline - Rice husk & $92,740.37$ & $92,740.37$ & - & 100.00 \\
\hline \multicolumn{5}{|l|}{ Off-season rice } \\
\hline - Rice straw & $106,863.13$ & $106,863.13$ & - & 100.00 \\
\hline - Rice husk & $45,798.48$ & $45,798.48$ & - & 100.00 \\
\hline \multicolumn{5}{|l|}{ Oil palm product } \\
\hline $\begin{array}{l}\text { - Palm leaves and } \\
\text { petiole }\end{array}$ & $16,650,355.53$ & $1,665,035.56$ & $14,985,319.97$ & 10.00 \\
\hline - Palm bunch & $3,778,804.10$ & $1,827,774.79$ & $1,951,029.32$ & 48.37 \\
\hline - Palm kernel Shell & $472,350.51$ & $472,350.51$ & - & 100.00 \\
\hline - Palm fiber & $2,243,664.98$ & $2,243,664.98$ & - & 100.00 \\
\hline \multicolumn{5}{|l|}{ Oil palm trunk } \\
\hline Palm trunk & $1,740,059.52$ & - & $1,740,059.52$ & - \\
\hline \multicolumn{5}{|l|}{ Rubber tree } \\
\hline - Root & $943,130.00$ & $188,626.00$ & $754,504.00$ & 20.00 \\
\hline - Sawdust & $565,878.00$ & $565,878.00$ & 0.01 & 100.00 \\
\hline - Wooden Slab & $2,263,511.99$ & $2,263,511.98$ & 0.02 & 99.99 \\
\hline - Wooden end & $2,263,511.99$ & $2,263,511.98$ & 0.02 & 99.99 \\
\hline \multicolumn{5}{|l|}{ Coconut } \\
\hline - Coconut shell & $132,830.00$ & $121,273.80$ & $11,556.20$ & 91.30 \\
\hline - Peel and spathe & $175,335.61$ & $173,406.92$ & $1,928.69$ & 98.90 \\
\hline $\begin{array}{l}\text { - Coconut blossom and } \\
\text { clas }\end{array}$ & $154,082.79$ & $29,892.07$ & $124,190.73$ & 19.40 \\
\hline \multicolumn{5}{|l|}{ Cashew nut } \\
\hline -Peel & $2,959.94$ & - & $2,959.94$ & - \\
\hline
\end{tabular}


Biomass can generate electrical energy, especially biomass gasification integrated combined heat and power (CHP) has got attention from the researcher. The cogeneration process is also able to produce electricity and heat in unique technology. Biomass gasification technology may cut the expense compared to gas turbines in power cogeneration. The applications of renewable energy sources in the CHP system have the potentiality of greenhouse gas emission reduction, which is very important for economic and environmental sustainability (Radenahmad et al. 2020). Pantaleo et al. demonstrated that the low scale CHP system (100 kWe to 1 MWe size) has consisted of two processes: firstly, biomass conversion through pyrolysis or gasification with the internal combustion engine and micro gas turbine; secondly, the combustion integration of boilers (fluidized bed) to drive micro gas turbine Stirling engines, steam turbines or Organic Rankine Cycle (Pantaleo et al. 2015). In biomass gasification integrated $\mathrm{CHP}$, the gasifier transforms the feedstock into syngas (mainly $\mathrm{CH}_{4}, \mathrm{H}_{2}, \mathrm{CO}, \mathrm{CO}_{2}$ ), which serves $\mathrm{CHP}$ to produce heat and power (Radenahmad et al. 2018, Radenahmad et al. 2019).

Biofuel technology can reduce the emission of $\mathrm{CO}_{2}$ and greenhouse gas produced by fossil fuels burning. The mitigation process to minimize the excess $\mathrm{CO}_{2}$ from the environment is more important than decreasing emission. Cellulosic biofuel can reduce fossil fuel consumption by developing energy and food security (Reza et al. 2020a).
The rice husks have tough, abrasive, low nutritious, and high ash content properties. For that is why it has minor usage in agricultural areas. As rice husks contain high silicon, its utilizations have increased significantly in recent periods. The rice husk is the source of silicon-based materials; like, silica, silicon carbide, silicon tetrachloride, silicon nitride, and zeolite (Sun et al. 2001).

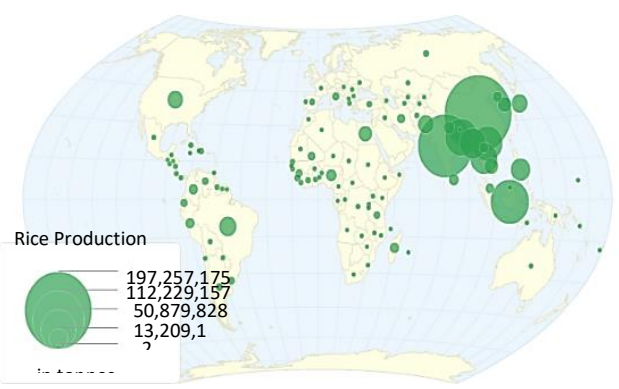

Fig. 1: Worldwide rice production.

The potential evaluation from the result shown in Table 2 reveals that 138,985.84 tons of rice husk can produce $13.18 \mathrm{MW}$ of power in 1 year if the power plant runs 24 hours/day and 330 days/year. This electricity quantity was not for full operation, but only when $20 \%$ of power plant efficiency was considered.

For rice husk utilization, the primary stage is to conduct the studies on material characterizations as there is not enough research done with the Thai Rice Husk. This paper has reported higher heating value analysis, moisture content study, pellet and bulk density measurement, scanning electron microscopy (SEM) and energy dispersive X-ray (EDX) analysis, and the potential evaluation for power generation of rice husk as a renewable energy resource. 
Table 2. Rice husk potential evaluation from the database in Thailand.

\begin{tabular}{ll}
\hline Properties & Value \\
\hline Biomass & Rice husk \\
Heating value (MJ/kg) & 13.52 \\
Biomass incurred (tons) & $8,145,269.20$ \\
Biomass used (tons) & $8,006,283.36$ \\
Biomass remained (tons) & $138,985.84$ \\
Heating value (TJ) & $1,879.09$ \\
$\begin{array}{l}\text { Crude oil equivalent } \\
\text { (ktoe) }\end{array}$ & 44.61 \\
$\begin{array}{l}\text { Equivalent to electricity } \\
\text { (GW-h) in 20\% power } \\
\text { plant efficiency } \\
\text { Installed capacity of } \\
\text { power plant (MW/year) } \\
\text { *Power plant operates } 24 \\
\begin{array}{l}\text { hours/day and 330 } \\
\text { days/year }\end{array}\end{array}$ & 104.39 \\
\end{tabular}

*1 ktoe $=42,120,000 \mathrm{MJ}=11,700,000 \mathrm{k}-\mathrm{Wh}$

\section{MATERIALS AND METHODS}

\section{Material Preparation}

Oryza Sativa L. (a type of rice husk, species from Yala, Thailand) was used for the experiments. The rice husk was made into powders, as shown in Figure 2, passed through a regular sieve number 60 to obtain powders in an average particle size of $0.250 \mathrm{~mm}$. The rice husk powder was then pelletized (without binder) to obtain 1 $\mathrm{g}$ pellet of $10 \mathrm{~mm}$ diameter for a higher heating value experiment. In pellet preparation, the sample was pressed by a manual hand pelletizer through the human, mechanical force in the clockwise direction.

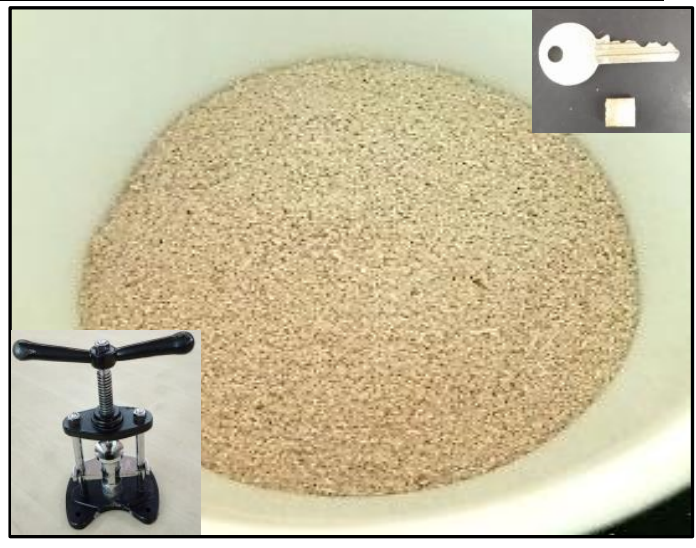

Fig. 2: Rice husk sample passed through sieve number 60 with a pellet and manual pelletizer.

\section{Higher Heating Value (HHV) Analysis}

A pellet sample was used for each experiment and engaged in a bomb calorimeter C-200 (P.A. HILTON LIMITED) to investigate the heat in biomass as heating value (Reza et al. 2019). The heating value is a significant property of biomass, which is also called the heat of combustion. In the ignition stage of the bomb calorimeter, the fire was introduced to biomass by intermediates of cotton thread and nichrome wire. Before placing it in the calorimeter, the weight of the biomass pellet, cotton thread, and nichrome wire was recorded in order to obtain the initial total mass. The temperature was recorded every 30 seconds manually after firing the biomass in the calorimeter. The raised temperature was calculated from the difference of firing point and ending point after the temperature was stable. Oxygen was used in the system at around 25 bars pressure for combustion purposes. Other constant parameters, such as the heat equivalent of the calorimeter and heating value of cotton fiber and nichrome cord, were taken from the calorimeter's calibration. The higher heating value was 
analyzed at constant volume employing equation (1).

$$
\mathrm{HHV}=\frac{\varepsilon \times \theta-\mathrm{m}_{\mathrm{c}} \times \mathrm{q}_{\mathrm{c}}-\mathrm{m}_{\mathrm{w}} \times \mathrm{q}_{\mathrm{w}}}{\mathrm{m}_{\mathrm{f}}}
$$

Where HHV is higher hating value $(\mathrm{kJ} / \mathrm{kg}), \varepsilon$ is the heat equivalent of the bomb $(J / K), \theta$ is temperature rise $(K), m_{c}$ is cotton mass $(\mathrm{g}), \mathrm{q}_{c}$ is heating value of cotton $(\mathrm{J} / \mathrm{g}), \mathrm{m}_{\mathrm{w}}$ is nichrome cord mass $(\mathrm{g}), \mathrm{q}_{\mathrm{w}}$ is the nichrome cord heating values $(\mathrm{J} / \mathrm{g})$, and $\mathrm{m}_{\mathrm{f}}$ is the sample weight $(\mathrm{g})$. The HHV is the energy content of any biofuel, which is tipically calculated per unit of solid mass $(\mathrm{MJ} / \mathrm{kg})$ and per unit liquid volume (MJ/l), and per unit gas volume (MJ/Nm3) (Reza et al. 2020a).

\section{Moisture Content (MC) Analysis}

Moisture content was examined using oven drying. The crucible was weighed as $\mathrm{w}_{\mathrm{c}}$. Biomass was kept in a ceramic container and measured as $\mathrm{w}_{\mathrm{i}}$. Then, the crucible was transferred in the oven and left at $105^{\circ} \mathrm{C}$ for 3 hours to remove the moisture. The final weight was collected after the oven operation as $\mathrm{w}_{\mathrm{f}}$. The $\mathrm{MC}$ values were calculated as equation (2) (Ahmed et al. 2018),

$$
\mathrm{MC}_{\mathrm{wb}}=\frac{\mathrm{w}_{\mathrm{i}}-\mathrm{w}_{\mathrm{f}}}{\mathrm{w}_{\mathrm{i}}-\mathrm{w}_{\mathrm{c}}} \times 100
$$

Where MCwb is the moisture content (wt.\%), $w_{c}$ is crucible weight $(g), w_{i}$ is the initial weight of crucible and sample before drying $(g)$, and $w_{f}$ is the final weight of crucible and sample after drying (g).

\section{Density Analysis}

About one gram of rice husk powder was pressed into a pellet and measured diameter, thickness, and weight. The density was calculated using equation (3) (Hossain et al. 2019), while bulk density was measured using a measuring cylinder.

$$
\mathrm{d}=\frac{\mathrm{m}}{\mathrm{v}}
$$

Where $d$ is the bulk density $\left(\mathrm{g} / \mathrm{cm}^{3}\right), \mathrm{m}$ is the mass of the pellet $(\mathrm{g})$, and $v$ is the volume of the pellet $\left(\mathrm{cm}^{3}\right)$.

\section{Scanning Electron Microscopy (SEM) and Energy Dispersive X-ray (EDX)}

The surface morphology of the rice husk and ash was examined by scanning electron microscope (SEM) of JEOL JSM$7610 \mathrm{~F}$ to observe the material's micro-scale feature. The solid materials were placed on the sample holder and conducted carefully to the analyzing chamber that was controlled the pressure in JEOL. The device employed electron dispersion to perform an SEM image on a computer screen connected. A device to identify the element's distribution is an energy dispersive X-ray (EDX) analyzer that reveals the elements in percentage. The EDX utilizes an effective $X$-ray to detect the chemical compositions of the sample.

\section{RESULTS AND DISCUSSION}

The biomass's main characteristics such as the higher heating value, the moisture content, the pellet density, and the bulk density, are listed in Table 3. The heating value is the indicator of the amount of heat released from biomass through complete combustion. The biomass compositions, moisture content, and ash content are the key parameters for influencing the calorific values (Sotelo et al. 2011).

It was achieved that the heating value 
and moisture contents were in good agreement with values from literature as compared in Table 4. Erol and Ku showed heating values of 20 different biomass types were in the range 15.41-19.52 MJ/kg (Erol et al. 2010). It revealed that the obtained heating value of rice husk was in the close range with other biomasses. The heating value of cultivated residue is one parameter that presenting the residues that can be transformed into bio-energy (Biswas et al. 2017). The heating value also varies by carbon level, where the value is high in high carbon level and low in high ash level (Reza et al. 2020b).

Table 3. The higher heating value, moisture content, pellet density, and bulk density of the rice husk

\begin{tabular}{cccc}
\hline $\begin{array}{c}\text { Calorific } \\
\text { value } \\
\text { (MJ/kg) }\end{array}$ & $\begin{array}{c}\text { Moisture } \\
\text { content } \\
\text { (wt.\%) }\end{array}$ & $\begin{array}{c}\text { Pellet } \\
\text { density } \\
\text { (g/cm3) }\end{array}$ & $\begin{array}{c}\text { Bulk } \\
\text { density } \\
\text { (g/cm3) }\end{array}$ \\
\hline 15.46 & 5.017 & 1.028 & 0.4187 \\
\hline
\end{tabular}

Ash level has a direct impact on heating value. The low content of volatile matter also affects the heating value reduction (Reza et al. 2020a). Although ash created from the combustion of rice husk can be utilized, it is not a desirable substance because of the clogging problem in energy-generating operation. A way to reduce ash is pre-treatment of rice husk by alkali (Bazargan et al. 2015). The higher heating value of biomass is advantageous in the reducing of heat supply that saves transportation expense (Tabakaev et al. 2017). With the heating value, the moisture content, density, and other properties are also important factors for considering biomass applications.

Table 4. The comparison of heating value and moisture content of rice husk from various resources.

\begin{tabular}{|c|c|c|c|}
\hline $\begin{array}{l}\text { Heating } \\
\text { value } \\
\text { (MJ/kg) }\end{array}$ & $\begin{array}{c}\text { Moisture } \\
\text { content } \\
\text { (wt.\%) }\end{array}$ & Resource & Reference \\
\hline 15.46 & 5.017 & Thailand & Present study \\
\hline 17.9 & 6.7 & Malaysia & $\begin{array}{c}\text { (Balasundram et } \\
\text { al. 2018) }\end{array}$ \\
\hline 12.87 & 10.89 & India & $\begin{array}{c}\text { (Biswas et al. } \\
\text { 2017) }\end{array}$ \\
\hline 16.08 & 9.2 & USA & (Yank et al. 2016) \\
\hline 16.53 & 11.33 & Brazil & (Brand et al. 2017) \\
\hline 16.29 & 8.54 & Bangladesh & $\begin{array}{c}\text { (Hossain et al. } \\
\text { 2017) }\end{array}$ \\
\hline 17.34 & 8.43 & Brunei & $\begin{array}{c}\text { (Abu Bakar et al. } \\
\text { 2013) }\end{array}$ \\
\hline
\end{tabular}

For the moisture content analysis, the moisture evaporation mechanism is when biomass is dried, the deposited moisture in material equilibrates with the environment relative humidity (Younis et al. 2018). The low moisture content (lower than $10 \mathrm{wt}$.\%) is expected for dry biomass as feedstock that improves heating value and combustion rate (Ahmed et al. 2018). By the advantages of low moisture content and uniform particle size in rice husk, the pretreatments (drying and grinding) are not required like wood products (Yoon et al. 2012). The moisture content achieved for this rice husk is $5.017 \%$, which is comparable with different rice husks (Alhinai et al. 2018). The plant's age, location, and preparation procedure are the main reasons for these differences (Reza et al. 2019). As the moisture content of this rice husk is low, it can be a suitable source for bioenergy production. Although rice husk has high ash content, it has 
advantages in low moisture, low sulfur, high basic density, and high fixed carbon level in the direct burning process (Brand et al. 2017). The lower MC of biomass was found to increase the heating value. High $M C$ and ash levels have adverse effects on ignition and combustion (Radenahmad et al. 2020).

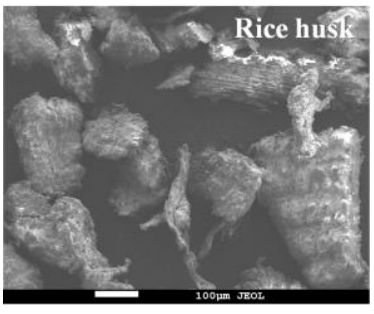

(a)

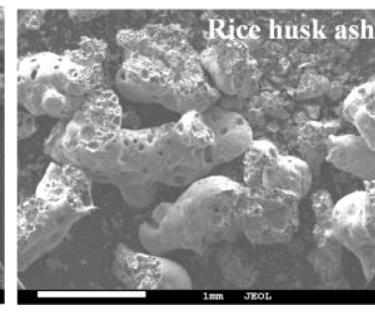

(b)
Fig. 3: SEM images of (a) rice husk and (b) rice husk ash after combustion in the bomb calorimeter.

The obtained bulk density of rice husk is $0.4187 \mathrm{~g} / \mathrm{cm}^{3}$. Usually, rice husk was found to have a low bulk density, generally below $200 \mathrm{~kg} / \mathrm{m}^{3}\left(0.2 \mathrm{~g} / \mathrm{cm}^{3}\right)$. It makes the challenge in the densification of biomass (into pellet or briquettes). The densification of biomass can enhance volumetric energy density, storage and transportation, combustion, and decrease particulate emissions and volatility (Yank et al. 2016).

The ash was produced from rice husk at the incinerating temperature of 550 to $700{ }^{\circ} \mathrm{C}$ by transforming the silica into an amorphous stage (Jaya et al. 2013). Scanning electron microscopy (SEM) and the energy-dispersive $\mathrm{X}$-ray (EDX) is one of the acceptable technology to estimate the morphological images and the elemental properties for biomass and ash (Ma et al. 2016). Raw rice husk and rice husk ash were examined by SEM to know the porosity and bulk microstructure, as shown in Figure 3. Rice husk samples were obtained in powder, and rice husk ash samples were achieved after combustion in bomb calorimeter from heating value analysis. It is observed that ash is a porous material because the new pores and cracks were formed with the increasing of temperature. The rice husk ash can be used as the catalysis in the pyrolysis process to upgrade biofuel quality. The biomass with high ash is required to include the ash removal system in the thermochemical conversion procedure (Ahmed et al. 2018). The pore of the material can be developed by zinc activation to enhance the porous structure. The porous carbon material is promising to be utilized as activated carbon (Reza et al. 2020c). The growth of the pores is enriched for the crystallinity of the minerals and the aromaticity of the ashes (Kim et al. 2012). Higher ash contents in the biomass are considered the higher availability of the mineral substances (Hidayat et al. 2018). Lower ash contents are appropriate for the production of activated carbon in water treatment. Rice husk ash also has catalytic activity for improved production in the thermochemical process (Reza et al. 2020d).

In XRD analysis, the X-ray is spotted by the energy-dispersive detector. The signal reveals a number $X$-ray count rate ( $y$-axis) against $X$-ray energy ( $X$-axis). The energy of $X$-ray makes the chemical elements formed to be detected, and the intensity of X-ray makes the concentration of chemical elements counted. Figure 4 confirmed the distribution of the elements detected by 
EDX. Rice husk has a higher content of carbon (C) and oxygen (O), while other metals like silicon (Si), calcium (Ca), magnesium (Mg), sodium $(\mathrm{Na})$, aluminum $(\mathrm{Al})$, phosphorous $(\mathrm{P})$, sulfur $(\mathrm{S})$, iron $(\mathrm{Fe})$ and potassium $(K)$ were higher in rice husk ash. $\mathrm{Ca}$ and Si's degradation rates are generally greater at higher temperatures than $\mathrm{K}$ and $\mathrm{Cl}$ (Parr et al. 2005). $\mathrm{Mg}$ and sodium ( $\mathrm{Na}$ ) can form bonds (ionic and covalent) with the organic molecules, and vaporization occurs at a higher temperature. S and $\mathrm{Al}$ are relatively stable and form complex organic compounds at lower temperatures (Schnitzer et al. 2007). Silicon dioxide $\left(\mathrm{SiO}_{2}\right)$ and aluminum oxide $\left(\mathrm{Al}_{2} \mathrm{O}_{3}\right)$ from silicon and aluminum were found in the ash surface as white dots (Parr et al. 2005). The pyrolytic volatiles breakdown into lower molecular organics and gases increased the proportion of ash (Thangalazhy-Gopakumar et al. 2010).

After rice husk combusted in the heating value experiment, the remaining ash contains much lower $\mathrm{C}$ and $\mathrm{O}$. The reduction of oxygen is related to dryness reactions (Ahmad et al. 2012). The O/C ratio has found 0.48 for rice husk, which is lower than the ash's value, 0.99. It is because the lower the ratios have, the higher the energy content. The $\mathrm{O} / \mathrm{C}$ ratio indicaties of the energy in the biomass based on oxygencarbon $(\mathrm{O}-\mathrm{C})$ bonds. A lower $\mathrm{O} / \mathrm{C}$ ratio is necessary to use it as solid fuel with higher energy content (McKendry 2002). The O/C ratios are used to measure the level of the aromaticity and polarity of the feedstock. If the temperature increase, the aromaticity

was increased, and the polarity was decreased in the sample (Reza et al. 2020b).
The $\mathrm{O} / \mathrm{C}$ ratio, which has been measured by EDX, was incredibly connected with the results of elemental analysis. The CHNS analyzer does not analyze oxygen content, whereas EDX can calculate it easily by elemental analysis (Budai et al. 2014).

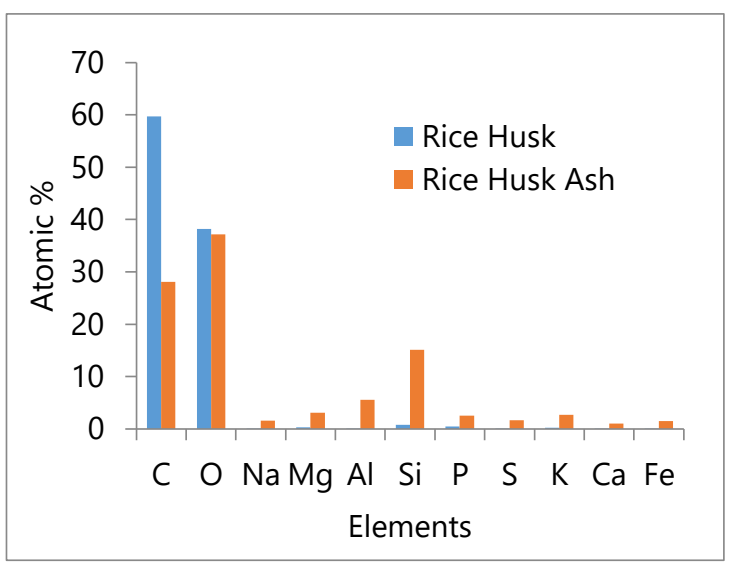

Fig. 4: The weight percentage of chemical elements detected from rice husk and rice husk ash.

In the rice husk combustion process, organic compounds, notably carbon, decreased while silica persists as it is the main component of rice husk. Rice husk generally contains lingo-cellulose and silica, especially in its ash, which has silica of $95 \%$ of the components (Yoon et al. 2012). The ash can be used in cement and steel production. A study revealed that silica derived from rice husk ash could improve the mechanical strength of refractory ceramics in substituting kaolin clay by $10 \%$ and $20 \%$ (Stochero et al 2017). In addition, rice husk ash has been utilized to enhance the mechanical performance of alloys (Tiwari et al. 2017).

\section{CONCLUSION}

The Thai Rice Husk species Oryza sativa 
Linn was characterized by higher heating value analysis, moisture content analysis, pellet density, bulk density, scanning electron microscopy, and energy dispersive X-ray. The heating value and moisture content are in better agreement for the energy production related to the literature values. The heating value showed that this rice husk is potential biomass to discharge heat energy that can be used as the feedstock for power generation. The low moisture content is the advantage of rice husk to overcome the high ash level of natural rice husk, especially low moisture content that can enhance the heating value in terms of heat released from combustion. The EDX reveals that rice husk and rice husk ash contain notable $\mathrm{O}, \mathrm{C}$, and especially $\mathrm{Si}$ is the main structure after combustion. The $\mathrm{O} / \mathrm{C}$ ratio represents the strong oxygencarbon bonds of the rice husk and ash. Rice husk also shows the simplicity in terms of sample preparations as its benefit in fuel transportation and management for small scale power generation. These properties revealed that rice husk could be a promising resource for power generation, especially in biomass gasification with combined heat and power generation processes.

\section{ACKNOWLEDGMENT}

NR, appreciates Universiti Brunei Darussalam Graduate Scholarship for the research scholarship at Faculty Integrated Technologies, Universiti Brunei Darussalam (UBD). The authors are grateful to Dr. Md Aminul Islam, Geological Sciences, UBD for SEM facility and environmental and life science program, faculty of science, and
UBD to assist in sample preparation.

\section{REFERENCES}

1. Hayati, N., Halim, A., Noor, S.S., Fazli, A., and Samad, A., (2019). "Effect of Gasification Temperature on Synthesis Gas Production and Gasification Performance for Raw and Torrefied Palm Mesocarp Fibre," ASEAN J. Chem. Eng., 19 (2), 120-129.

2. Reza, M.S., Ahmed, A., Caesarendra, W., Abu Bakar, M.S., Shams, S., Saidur, R., Aslfattahi, N., and Azad, A.K., (2019). "Acacia Holosericea: an Invasive Species for Bio-char, Bio-oil and Biogas Production," Bioengineering, 6 (2), 33.

3. Yoon, S.J., Son, Y. II, Kim, Y.K., and Lee, J.G., (2012). "Gasification and power generation characteristics of rice husk and rice husk pellet using a downdraft fixed-bed gasifier," Renewable Energy, 42, 163-167.

4. Rizkiana, J., Handoko, S., Wulandari, W., Ridha, M.A., Prasetyo, H.A., and Sasongko, D., (2018). "Hybrid Coal: Effects Of Composition And Copyrolysis Retention Time in Low Rank Coal and Biomass Waste Co-pyrolysis Process on The Product's Yield," ASEAN J. Chem. Eng., 18 (1), 68-75.

5. Ahiduzzaman, M., and Sadrul Islam, A.K.M., (2016). "Preparation of porous bio-char and activated carbon from rice husk by leaching ash and chemical activation," SpringerPlus, 5(1), 1248.

6. Radenahmad, N., Abdul Rahman, I.S., Haji Morni, N.A., and Azad, A.K., (2018). "Acacia-Polyethylene Terephthalate Co- Gasification as Renewable Energy Resource," International Journal of Renewable Energy Research, 8(3).

7. Pranolo, S.H., Bindar, Y., Sasongko, D., and Susanto, H., (2010). "Modeling and Simulation of a Separate Line Calciner 
Fueled with a Mixture of Coal and Rice Husk," ASEAN J. Chem. Eng., 10 (1), 2834.

8. Radenahmad, N., Tasfiah, A., Saghir, M., Taweekun, J., Saifullah, M., Bakar, A., Reza, S., and Kalam, A., (2020). "A review on biomass derived syngas for SOFC based combined heat and power application," Renewable Sustainable Energy Rev., 119(March), 109560.

9. Pantaleo, A.M., Camporeale, S., and Fortunato, B., (2015). "Small scale biomass CHP: Techno-economic performance of steam vs gas turbines with bottoming ORC," Energy Procedia, $82,825-832$.

10. Radenahmad, N., Taweekun, J., Afif, A., Park, J.Y., Zaini, J., and Azad, A.K., (2019). "Syngas Fuelled High Performance Solid Oxide Fuel Cell," ECS Transactions, 91(1), 1621-1629.

11. Reza, M.S., Islam, S.N., Afroze, S., Bakar, M.S.A., Sukri, R.S., Rahman, S., and Azad, A.K., (2020). "Evaluation of the bioenergy potential of invasive Pennisetum purpureum through pyrolysis and thermogravimetric analysis," Energy, Ecology and Environment, 5(2), 118-133.

12. Sun, L., Carbide, S., and Sic, P., (2001). "Silicon-Based Materials from Rice Husks and Their Applications," Ind. Eng. Chem. Res., 40(25), 5861-5877.

13. Ahmed, A., Hidayat, S., Bakar, M.S.A., Azad, A.K., Sukri, R.S., and Phusunti, N., (2018). "Thermochemical characterization of Acacia auriculiformis tree parts via proximate, ultimate, TGA, DTG, calorific value and FTIR spectroscopy analyses to evaluate their potential as a biofuel resource," Biofuels, 0(0), 1-12.

14. Hossain, N., Zaini, J., Mahlia, T.M.I., and Azad, A.K., (2019). "Elemental, morphological and thermal analysis of mixed microalgae species from drain water," Renewable Energy, 131, 617-
624.

15. Sotelo, C., Agostinho, D., Garcia, R.A., and Weber, J.C., (2011). "Calorific value of Prosopis africana and Balanites aegyptiaca wood: Relationships with tree growth, wood density and rainfall gradients in the West African Sahel," Biomass Bioenergy, 35, 346-353.

16. Erol, M., Haykiri-Acma, $H_{\text {., }}$ and Küçükbayrak, S., (2010). "Calorific value estimation of biomass from their proximate analyses data," Renewable Energy, 35, 170-173.

17. Biswas, B., Pandey, N., Bisht, Y., Singh, R., Kumar, J., and Bhaskar, T., (2017). "Pyrolysis of agricultural biomass residues: Comparative study of corn cob, wheat straw, rice straw and rice husk," Bioresour. Technol., 237, 57-63.

18. Reza, M.S., Afroze, S., Bakar, M.S.A., Saidur, R., Aslfattahi, N., Taweekun, J., and Azad, A.K., (2020). "Biochar characterization of invasive Pennisetum purpureum grass: effect of pyrolysis temperature," Biochar, 2(2), 239-251.

19. Balasundram, V., Ibrahim, N., Kasmani, R.M., Hamid, M.K.A., Isha, R., Hasbullah, H., and Ali, R.R., (2018). "Thermogravimetric catalytic pyrolysis and kinetic studies of coconut copra and rice husk for possible maximum production of pyrolysis oil," J. Cleaner Prod., 167, 218-228.

20. Yank, A., Ngadi, M., and Kok, R., (2016). "Physical properties of rice husk and bran briquettes under low pressure densification for rural applications," Biomass Bioenergy, 84, 22-30.

21. Brand, M.A., Jacinto, R.C., Antunes, R., and da Cunha, A.B., (2017). "Production of briquettes as a tool to optimize the use of waste from rice cultivation and industrial processing," Renewable Energy, 111, 116-123.

22. Hossain, M.S., Islam, M.R., Rahman, M.S., Kader, M.A., and Haniu, H., (2017). 
"Biofuel from Co-pyrolysis of Solid Tire Waste and Rice Husk," Energy Procedia, 110 (December 2016), 453-458.

23. Abu Bakar, M.S., and Titiloye, J.O., (2013). "Catalytic pyrolysis of rice husk for bio-oil production," J. Anal. Appl. Pyrolysis, 103, 362-368.

24. Bazargan, A., Bazargan, M., and McKay, G., (2015). "Optimization of rice husk pretreatment for energy production," Renewable Energy, 77, 512-520.

25. Tabakaev, R., Shanenkov, I., Kazakov, A., and Zavorin, A., (2017). "Thermal processing of biomass into highcalorific solid composite fuel," J. Anal. Appl. Pyrolysis, 124, 94-102.

26. Younis, M., Alnouri, S.Y., Abu Tarboush, B.J., and Ahmad, M.N., (2018). "Renewable biofuel production from biomass: a review for biomass pelletization, characterization, and thermal conversion techniques," International Journal of Green Energy, 15(13), 837-863.

27. Alhinai, M., Azad, A.K., Bakar, M.S.A., and Phusunti, N., (2018). "Characterization and Thermochemical Conversion of Rice Husk for Biochar Production," International Journal of Renewable Energy Research (IJRER), 8(3), 1648-1656.

28. Jaya, R.P., Ahmad, Z.A., and Amin, Z.M., (2013). "Properties of Mortar Containing Rice Husk Ash at Different Temperature and Properties of Mortar Containing Rice Husk Ash at Different Temperature and Exposed to Aggressive Environmen," Adv. Mater. Res., 620, 87-93.

29. Ma, X., Zhou, B., Budai, A., Jeng, A., Hao, X., Wei, D., Zhang, Y., and Rasse, D., (2016). "Study of Biochar Properties by Scanning Electron Microscope Energy Dispersive X-Ray Spectroscopy (SEM-EDX)," Communications in Soil Science and Plant Analysis, 47 (5), 593601.
30. Reza, M.S., Hasan, A.B.M.K., Afroze, S., Muhammad, S., Bakar, A., Taweekun, J., and Azad, A.K., (2020). "Analysis on Preparation , Application , and Recycling of Activated Carbon to Aid in COVID-19 Protection," International Journal of Integrated Engineering, 12(5), 233-244.

31. Kim, K.H., Kim, J.-Y.Y., Cho, T.-S.S., and Choi, J.W., (2012). "Influence of pyrolysis temperature on physicochemical properties of biochar obtained from the fast pyrolysis of pitch pine (Pinus rigida)," Bioresour. Technol., 118, 158-162.

32. Hidayat, S., Abu Bakar, M.S., Yang, Y., Phusunti, N., and Bridgwater, A.V., (2018). "Characterisation and PyGC/MS analysis of Imperata Cylindrica as potential biomass for bio-oil production in Brunei Darussalam," J. Anal. and Appl. Pyrolysis, 134, 510-519.

33. Reza, M.S., Yun, C.S., Afroze, S., Radenahmad, N., Bakar, M.S.A., Saidur, R., Taweekun, J., and Azad, A.K., (2020). "Preparation of activated carbon from biomass and its' applications in water and gas purification, a review," Arab Journal of Basic and Applied Sciences, 27 (1), 208-238.

34. Parr, J.F., and Sullivan, L.A., (2005). "Soil carbon sequestration in phytoliths," Soil Biol. Biochem., 37 (1), 117-124.

35. Schnitzer, M.I., Monreal, C.M., Jandl, G., Leinweber, P., and Fransham, P.B., (2007). "The conversion of chicken manure to biooil by fast pyrolysis II. Analysis of chicken manure, biooils, and char by curie-point pyrolysis-gas chromatography/mass spectrometry (Cp Py-GC/MS)", J. Environ. Sci. Health, 43 (1), 81-95.

36. Thangalazhy-Gopakumar, S., Adhikari, S., Ravindran, H., Gupta, R.B., Fasina, O., Tu, M., and Fernando, S.D., (2010). "Physiochemical properties of bio-oil produced at various temperatures 
from pine wood using an auger reactor," Bioresour. Technol., 101 (21), 8389-8395.

37. Ahmad, M., Lee, S.S., Dou, X., Mohan, D., Sung, J.K., Yang, J.E., and Ok, Y.S., (2012). "Effects of pyrolysis temperature on soybean stover- and peanut shell-derived biochar properties and TCE adsorption in water," Bioresour. Technol., 118, 536544.

38. McKendry, P., (2002). "Energy production from biomass (part 1): overview of biomass," Bioresour. Technol., 83 (1), 37-46.

39. Budai, A., Wang, L., Gronli, M., Strand, L.T., Antal, M.J.J., Abiven, S., DieguezAlonso, A., Anca-Couce, A., and Rasse, D.P., (2014). "Surface Properties and Chemical Composition of Corncob and Miscanthus Biochars: Effects of Production Temperature and Method," J. Agric. Food Chem., 62 (17), 37913799.

40. Stochero, N.P., Marangon, E., Nunes, A.S., and Tier, M.D., (2017). "Development of refractory ceramics from residual silica derived from rice husk ash and steel fibres," Ceram. Int., 43(16), 13875-13880.

41. Tiwari, S., and Pradhan, M.K., (2017). "Effect of rice husk ash on properties of aluminium alloys: A review," Materials Today: Proceedings, 4 (2), 486-495. 